Old Dominion University

ODU Digital Commons

Information Technology \& Decision Sciences

Faculty Publications

Information Technology \& Decision Sciences

2019

\title{
A Systems Dynamics Simulation Study of Network Public Opinion Evolution Mechanism
}

Ge Gao

Tianyong Wang

Xianrong Zheng

Old Dominion University, x1zheng@odu.edu

Yong Chen

Xiaobo Xu

Follow this and additional works at: https://digitalcommons.odu.edu/itds_facpubs

Part of the Communication Technology and New Media Commons, Political Science Commons, Public Affairs Commons, and the Social Media Commons

\section{Original Publication Citation}

Gao, G., Wang, T., Zheng, X., Chen, Y., \& Xu, X. (2019). A systems dynamics simulation study of network public opinion evolution mechanism. Journal of Global Information Management, 27(4), 189-207. doi:10.4018/JGIM.2019100110

This Article is brought to you for free and open access by the Information Technology \& Decision Sciences at ODU Digital Commons. It has been accepted for inclusion in Information Technology \& Decision Sciences Faculty Publications by an authorized administrator of ODU Digital Commons. For more information, please contact digitalcommons@odu.edu. 


\section{WARNING CONCERNING COPYRIGHT RESTRICTIONS}

The copyright law of the United States (Title 17, United States Code) governs the making of photocopies or other reproductions of copyrighted materials. Under certain conditions specified in the law, libraries and archives are authorized to furnish a photocopy or other reproduction. One of these specified conditions is that the photocopy or reproduction is not to be "used for any purpose other than private study, scholarship, or research". If a user makes a request for, or later uses, a photocopy or reproduction for purposes in excess of "fair use", that user may be liable for copyright infringement. This institution reserves the right to refuse to accept a copying order if, in its judgment, fulfillment of the order would involve violation of copyright law. 


\title{
A Systems Dynamics Simulation Study of Network Public Opinion Evolution Mechanism
}

\author{
Ge Gao, Jilin University, Changchun, China \\ Tianyong Wang, Construction Environmental Protection Bureau of Hengqin New District, Zhuhai, China \\ Xianrong Zheng, Old Dominion University, Norfolk, USA \\ Yong Chen, Texas A\&M International University, Laredo, USA \\ Xiaobo Xu, American University of Sharjah, Sharjah, UAE
}

\begin{abstract}
The factors that affect formation and dissemination of public opinion have been studied for a long time. However, the findings are disparate and fragmented, given the characteristics of netizens and new media in the Big Data era. To this end, this article introduces eight mechanisms working on formation and dissemination of public opinion on network. Based on system dynamics, this article further proposes a comprehensive causal relationship model to explore the factors affecting the consequence of public opinion on network. Particularly, the role of government is taken into consideration in this model. A simulation with Vensim PLE is conducted. The results of the simulation indicate that group polarization among netizens, opinion leaders, the quantity of media audience, the frequency of media report, government attention, and warning mechanism for public opinion crisis affect the consequence of public opinion on network significantly. Implications of the findings are discussed.
\end{abstract}

\section{KEYWORDS}

Network, Public Opinion, Simulation, System Dynamics

\section{INTRODUCTION}

Public opinion has been defined as a collection of views regarding an issue that affects many (Corbett, 1991). It is a process associated with multiple factors (Foote \& Hart, 1953; Price \& Roberts, 1987; Noelle-Neumann, 1993). According to Davison (1958), public opinion is "the result of psychological and social processes that lead to a situation in which the behavior of each member of a public in regard to an issue is conditioned by his expectation that other members of the public hold similar attitudes on the same issue" (p91). The narrow sense of public opinion is an expression of the general public's attitudes about government, whereas the broad sense of public opinion is an expression of the general public's living conditions, social environment, and attitudes on different issues (Katz \& Lazarsfeld, 1955). 
The study of the public opinion process often includes psychological components (attitudes and beliefs), social components (group discussion and norms), and political components (elite perspectives presented in the media) components (Hoffman, Glynn, Huge, Sietman, \& Thomson, 2007). Two theories have been developed to explain how public opinion forms and influences people in the era of traditional media when a minority of members spread ideas to others in a society. One is the influentials theory, and the other is diffusion of innovations theory. According to these two theories, influentials play different roles in formation and dissemination of public opinion (Domingos \& Richardson, 2001; Katz \& Lazarsfeld, 1955; Rogers \& Cartano, 1962; Watts \& Dodds, 2007).

The development of new technologies, particularly the Internet, provides new platforms for formation and dissemination of public opinion (Cui \& Jiang, 2018; Fan, 2017). Scholars have explored the characteristics of public opinion and how public opinion evolves on network. Particularly, diverse models have been proposed for studying public opinion. For example, Goldenberg, Libai, and Muller (2001) present a cascade model to explain the transmission process of public opinion on network. In addition, serval other models have been proposed in recent years, such as infection model (Su \& Lan, 2013), network public opinion dredge model (Song, Zhu, \& Huang, 2014), and system dynamics model (Di, Zeng, \& Le, 2012). Recently, Zeng, Wang, and Chen (2014) compare several transmissions and spreading models for public opinion based on the macro and micro rules of public opinion.

Other than proposing models for studying public opinion, scholars have also explored the factors that affect public opinion. For instance, Chong and Druckman (2007b) point out that the transmission process in network affects the eruption and spreading of public opinion. Bennett and Iyengar (2008) investigate how audiences are affected by the development of network and the management of government when public opinion is transmitted in network. Ding (2015) explores how public opinion transmission evolved in network via simulation. Zhou, Wang, and Fang (2012) analyze the transmission mechanism of public opinion based on a case study. Chen and Chen (2016) adopts national cultural dimensions, the index of cultural distance, and the social influence theory to explore how culture impacts the opinion influence occurring in social media-based brand communities.

Although scholars have explored the factors that affect formation and dissemination of public opinion on network from diverse perspectives, the findings are disparate and fragmented. To this end, this paper adopts system dynamics and explores the factors affecting the consequence of public opinion on network. Particularly, the role of government is taken into consideration. Based on system dynamics, this paper proposes a comprehensive causal relationship model and then conduct a simulation with Vensim PLE. The results of the simulation indicate that group polarization among netizens, opinion leaders, the quantity of media audience, the frequency of media report, government attention, and warning mechanism for public opinion crisis affect the consequence of public opinion on network significantly.

The remainder of the paper is organized as follows. We briefly present the research on public opinion. Additionally, eight mechanisms working on the evolution of public opinion on network are introduced. Furthermore, we discuss factors affecting the consequence of public opinion on network. We then propose a comprehensive causal relationship mode. What's more, a simulation for the evolution of public opinion on network is implemented. Finally, we concludes the paper and suggests directions for future research.

\section{LITERATURE REVIEW}

The formation of public opinion is the result of social interactions and communication (Powell, 1951). Scholars have long argued that opinions develop through a dynamic discourse between cognitive components and social components (Hoffman, Glynn, Huge, Sietman, \& Thomson, 2007). According to Davison (1958), formation and dissemination of public opinion involves four steps, namely the formation of individual attitudes and opinions, group opinion processes, personal sampling, and inter-group communication. 
Hoffman, Glynn, Huge, Sietman, and Thomson (2007) point out that public opinion process consists of interactions among various factors, including relevant predispositions, media use, interpersonal discussion, and perceptions of community opinion. Scholars have explored how individuals form opinions (e.g. Price, 1989; Pan \& Kosicki, 1996), how individuals conform to majority pressure (e.g. Asch, 1956; Moscovici, 1985; Blanton \& Christie, 2003), and how individuals are influenced by mass media presentations of public opinion (e.g. Mutz \& Soss, 1997). These components overlap and intertwine to form public opinion (Hoffman, Glynn, Huge, Sietman, \& Thomson, 2007).

In existing literatures, two theories have been developed to explain how public opinion forms and influences people. One is the influentials theory, and the other is diffusion of innovations theory. The influentials theory states that a minority of individuals, namely influential or opinion leaders, excel in persuading others in a society (Rogers \& Cartano, 1962). The individuals possess qualities that make them exceptionally persuasive in spreading ideas to others (Cha, Haddadi, Benevenuto, \& Gummadi, 2010). Public opinion often depends on how these individuals choose to frame issues (Chong \& Druckman, 2007a). Particularly, Katz and Lazarsfeld (1955) propose the two-step flow communication model indicating that information from media is first received by opinion leaders, who then transmit the information to the majority of society. They define opinion leaders as "...the individuals who were likely to influence other persons in their immediate environment..." (p. 3). Opinion leaders give their influential comments and opinions, provide guiding ideas, agitate and guide the public to understand social problems (Lazarsfeld, Berelson, \& Gaudet, 1944). Because opinion leaders are informed, respected, and well-connected, a large-scale chain-reaction of influence driven by word-of-mouth can be achieved by targeting them (Katz \& Lazarsfeld, 1955).

It has been long believed that influentials are important to the formation of public opinion (Watts \& Dodds, 2007). However, the influentials theory does not take into account the role of ordinary individuals. By conducting a simulation, Watts and Dodds (2007) find that influentials initiate more frequent and larger cascades than average individuals, but they are neither necessary nor sufficient for all diffusions. Watts (2007) concludes that a trend's success in a network depends not on the person who starts it, but on how susceptible the society is overall to the trend.

In contrast, the diffusion of innovations theory explains the role of influentials differently. Bineham (1988) presents the one-step, or hypodermic, model indicating that individuals are influenced by media like atomized objects. The influentials are called innovators (Rogers \& Cartano, 1962). The role of influential is deemphasized and the factors that determine influence consist of the interpersonal relationship among ordinary individuals and the readiness of a society to adopt an innovation (Watts \& Dodds 2007; Domingos \& Richardson 2001). In the new information age, particularly, people make choices based on the opinions of their peers and friends, rather than listening to influentials (Domingos \& Richardson 2001).

\section{EIGHT MECHANISMS WORKING ON THE EVOLUTION OF PUBLIC OPINION ON NETWORK}

Public opinion on network refers to attitude, suggestion, and mood expressed by the public about social events over network ( $\mathrm{Li}, 2009$; Zeng, 2012). In big data era, huge amount of information in the Internet change quickly (Bi, Xu, \& Wang, 2014; Li, Xu, \& Zhao, 2015; Li, Xu and Zhao 2018; Wang, Chaudhry, \& Li, 2016; Whitmore, Agarwal, \& Xu, 2015; Xu \& Duan, 2018; Xu, He, \& Li, 2014; Xu, Xu, \& Li, 2018). When certain events occur, public opinion about them form and spread quickly on network.

Formation of public opinion on network involves context, big data, and disturbing factors (Chen, Chen, Gorkhali, Lu, Ma, \& Li, 2016). Eight mechanisms work on the evolution of public opinion on network, namely trigger mechanism, diffusion mechanism, opinion convergence mechanism, selfserving mechanism, polarization mechanism, clue accumulation mechanism, cycle mechanism, and 
disturbing mechanism. The eight mechanisms influence each other and drive public opinion evolve on network (Figure 1).

When an event triggers the formation and spreading of public opinion on network, trigger mechanism takes into effect. As more netizens become interested in the event, the authenticity of this event turns into the focus. The impact of public opinion grows as well. In this case, the formation of public opinion is related with the sensitivity of network, which changes with social environment.

When netizens release their opinions through the network, diffusion mechanism begin to work. Netizens influence each other by their opinions. Opinions diffuse through the highly interactive network from the close nodes to the remote ones. Each netizen participates in the diffusion and influences others.

After netizens express their opinion and communicate with each other to promote the evolution of public opinion. In this process, opinion convergence mechanism works. If the evolution continues, new opinion will be generated or disappeared. Theoretically, only one opinion will be retained. Nowadays, the opinion aggregation process becomes shorter due to new techniques.

Self-serving mechanism refers to the process in which netizens maximize their benefits when public opinion spreading on network. As the most powerful driving force, this mechanism exists in every stage of the evolution of public opinion on network.

Polarization mechanism works for establishing polarized public opinion on network in netizens communication process and group decision-making process. Radical opinion is much easier to be concerned and polarized. A slight change may trigger unimaginable opinion evolution in the butterfly effect.

Clue accumulation mechanism aims for strengthen the feeling and memory of netizens. Public opinion can be diffused by multiple systems on network, such as word system, image system, and sound system. Netizens' feeling and memory can be enhanced with these systems.

Cycle mechanism works for driving evolution of public opinion and form new opinion. In this process, the network public opinion evolves with spread, derivation, and coupling. The information circles around public opinion and netizens and interlocks each other.

Figure 1. The eight mechanisms working on the evolution of public opinion on network

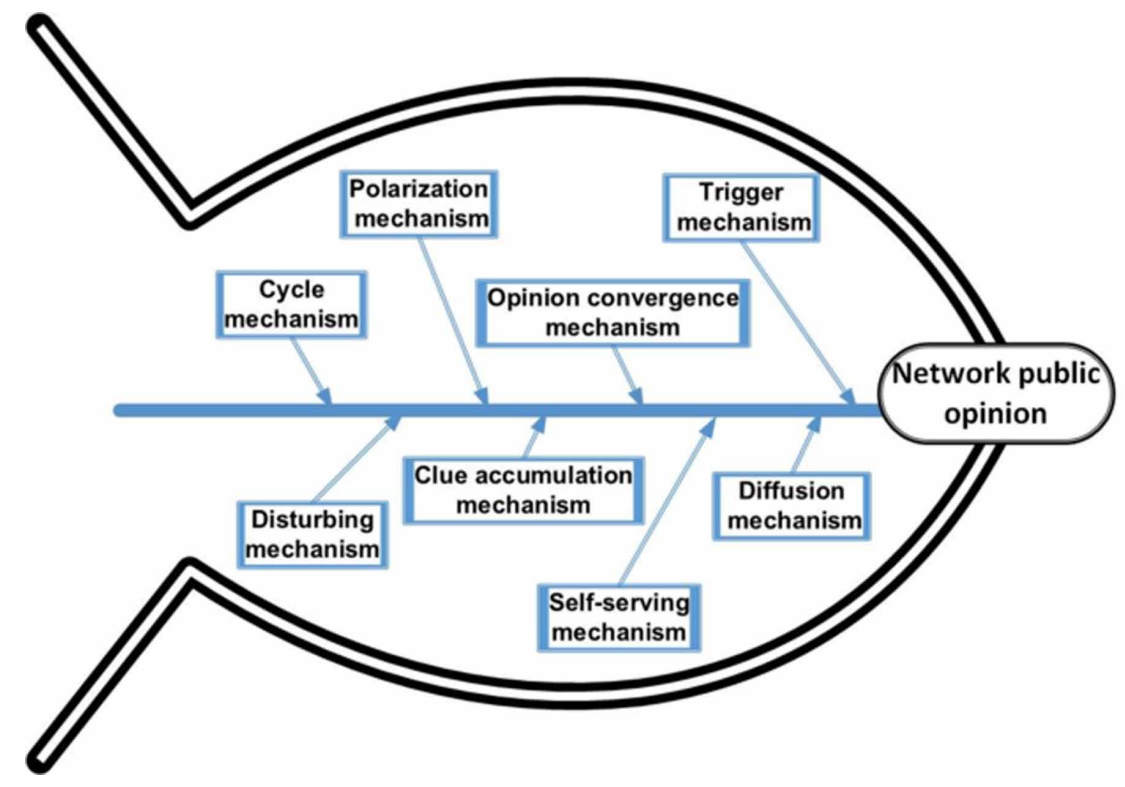


When disturbing mechanism works, public opinion spreads synchronously on network with noises that change the original information. The noises include obstruct, distort, and interfere factors.

\section{FACTORS AFFECTING THE CONSEQUENCE OF PUBLIC OPINION ON NETWORK}

In the context of big data, the network public opinion system is complex, dynamic, and multiple. The lifecycle of public opinion on network consist of the stages of formation, enhancement, weakening, and regression. The influence of the network public opinion depends on: 1) how an event is spread over network; 2) how netizens discusses and evaluates the event after government's intervention and the implementation of measures; 3) how often public opinion is discussed on network; and 4) what impact on the real world is brought by the continuous spread of public opinion on network. Five key factors affect the consequence of public opinion on network, namely netizens' concerning degree, netizens' opinion tendency, netizens' participation, media, and measures from government. In this paper, we focus on the roles that netizens, new media, and government play on the consequence of public opinion on network. Figure 2 shows the factors affecting the consequence of public opinion on network.

\section{Netizens}

Public opinion on network originates from netizens' attention and discussion. When certain events happen, netizens arouse strong repercussions and high attention immediately. Event sensitivity refers to the degree of reaction of events to external stimuli, including positive and negative evaluation of netizens and measures taken by government. Only novel events with high sensitivity can attract attention from netizens (Wang, 2003). In addition, events with significant impacts will generate strong public opinion (Guo, Shao, \& Yan, 2015). Once public opinion is generated, discussion about the events need to be continuous. When high relevance exists between public opinion and netizens' interests, long time attention and discussion will occur. As public opinion evolves, media and government might be involved. As time goes by, public opinion begins to regress and finally fade away.

Figure 2. Factors affecting the consequence of public opinion on network

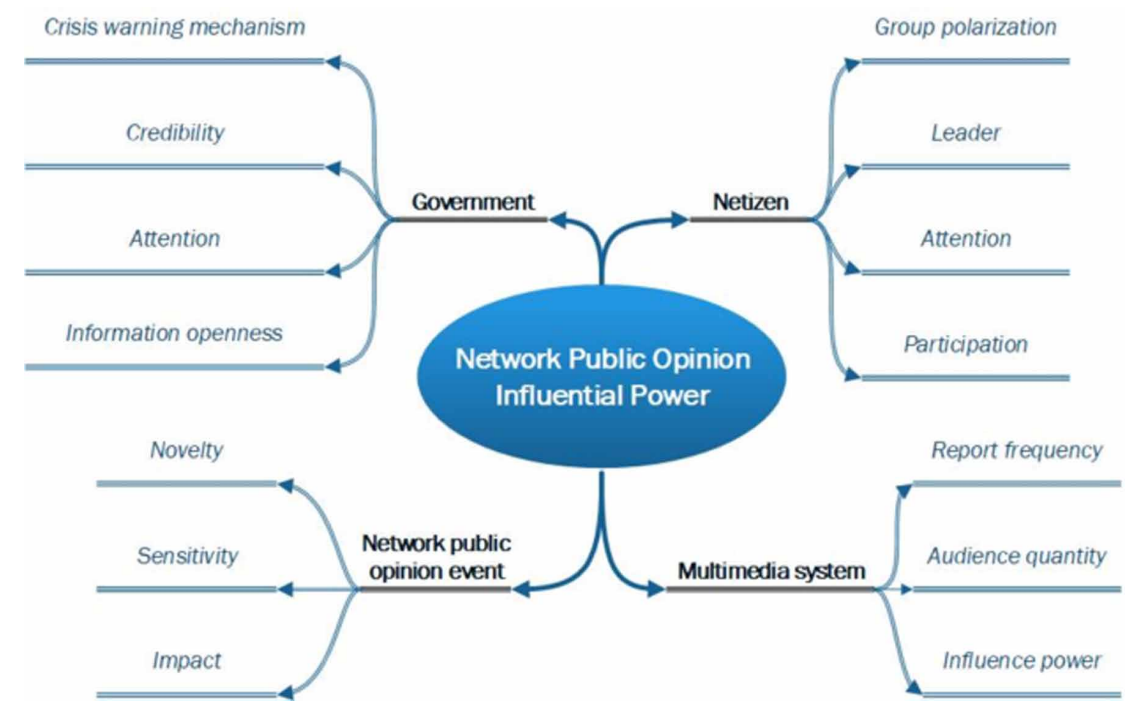


Netizens are the subject of public opinion on network. A netizen becomes a node on the network, in which information is disseminated (Yuan \& Xu, 2015). When public opinion spreads on network, netizens receive information and express their opinion. Therefore, they are transmission nodes as well as receiving nodes. When information goes through netizens, one tendency opinion stream or multiple tendency opinion streams will form. In a single opinion stream, the inner opinion is a unity. In contrast, in multiple opinion streams, opinions tend to be opposite. On one hand, netizens will generate a positive or negative impact on the consequence of public opinion on network. On the other hand, media and government will indirectly affect the consequence of public opinion on network.

Netizens' opinion falls into three categories: support, opposing, and neutral. Activity coefficient of netizens refers to the degree of attention that netizens pay to certain events and the frequency at which these events are discussed. The larger the active coefficient is, the stronger the effect of netizens is. At the stage when public opinion is generated on network, a large activity coefficient means a higher possibility that a certain event will attract attention and promote discussion among netizens. When public opinion develops, the value of activity coefficient indicates the possibility of continuous public opinion evolution. When public opinion regresses on network, activity coefficient is low. This indicates that netizens' attention and public opinion demise. In this paper, we choose the number of new posts as activity coefficient.

Group polarization of the network public opinion evolution is defined for the situation when the tendency of the netizen group evaluation and the positive flow rate are higher than those of an individual netizen. The opinion of an individual netizen is susceptible to be influenced by other people, especially opinion leaders. When group polarization takes effect, a netizen's judgement is affected. $\mathrm{He}$ or she tends to imitate others. In addition, similar opinions are much easier to become one or several multiple opinion streams because of high anonymity and high interactivity of the Internet. While opposing opinions tend to be inversed, many different opinion streams will fiercely collide to promote disseminating public opinion on network (Xie, 2014).

In the context of new media, an opinion leader is a special netizen who has authority and expresses opinions frequently on the network. His or her opinion is often turned into a focus opinion and sometimes has a leading role in the evolution of public opinion on network (Xie, 2014). In online society, opinion leaders are the main information sources for users (Ma, \& Liu, 2014). According to Stelzner (2010), about $78 \%$ of users in social network communities trust opinion leaders' recommendations for products and services. Other than promoting the formation of online public opinion, opinion leaders can influence the direction of public opinion and guide the partial opinion to become the public opinion (Liu, 2001). Thus, opinion leaders have significant influence on the consequence of public opinion on network.

The main point of system dynamics is that the behavior of a system is determined by its structure. According to Tian, $\mathrm{Xu}$, and $\mathrm{Ma}$ (2011), system dynamics can describe positive and negative feedbacks among variables in a system with graphical representation (Tian, Xu, \& Ma, 2011). The cause-andeffect diagram uses arrows to link causal relationship. The + sign and - sign indicate variables' polarity. Based on the discussion of netizen attention, netizen participation, group polarization, and opinion leader in the consequence of public opinion on network, this paper proposes a causal relationship model for netizens' role as shown in Figure 3.

\section{New Media}

The diffusion of Internet, mobile communication, digital media, and social software have prompted the development of horizontal networks of interactive communication, which includes the multimodal exchange of interactive messages from many to many both synchronous and asynchronous (Castells, 2007). The new format of communication makes public opinion on network map public opinion in real life (Ning,Yijun, Ruya, \& Qianqian, 2012). Due to its quickness, interaction, openness, fictitiousness and abruptness, the Internet has become a channel for individuals to express their opinions and to communicate with each other. Other than providing real information that are beneficial to the 


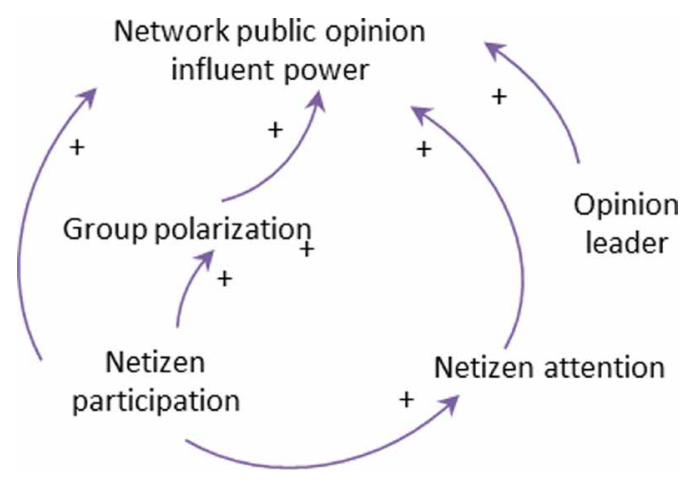

development of society, the Internet also contains reactionary, violence, rumors, attacking and defaming, as well as much false information (Ning, Yijun, Ruya, \& Qianqian, 2012).

New media, particularly Facebook, WeChat, Instagram, blogs, microblogging, and forums, become the carrier for the diffusion of public opinion. With the rapid development of new media, information becomes more open and diversified. Meanwhile, media become decentralized as well. New media are changing the mode for information dissemination and provide new channels for information achieve. In new media era, nodes in information dissemination include network and netizens. Because information supplier and information receiver become a unity, public opinion spread quicker than before on network. New media play a key role in the evolution of public opinion on network. This role is determined by public opinion' continuous diffusion time, which is the critical factor of network public opinion dissipation.

Media influence means the extent to which netizens' opinion and attitude are affected by evaluation of public opinion disseminated via media. Specifically, new media guide and influence netizens attitude. Media influence relies on the confidence and the quantity of audiences. In addition, media size, mode of media dissemination, dissemination platform, and staff profession affect media influence as well (Wei, 2014). At the stage when public opinion is generated, the public pay more attention to events reported by influential media. When public opinion develops, timely reporting, the types of new media, and evaluation guidance from new media impact the opinion tendency. Therefore, powerful media have stronger influence on public opinion.

Media spread speed is a comprehensive reflection about the frequency that events are reported, the number of netizens influenced by reporting, and the degree how netizens are affected. When netizens pay more attention to certain events, media report these events more often. Thus, media transmission rate is high in this case. In other words, a higher media transmission rate attracts more attention from netizens. Based on the discussion of new media, media influence, and media spread speed, this paper proposes a causal relationship model for media's role as shown in Figure 4.

\section{Government}

Government plays an important role at each stage of the evolution of public opinion on network. Whether public events are resolved in a proper way and whether public opinion fade timely rely on government greatly. When public events occur, government needs to pay timely attention, to release authoritative information, to reply inquiries from public, and to update policies and regulations. In this way, public opinion can be guided in a proper way, so that public crises can be avoided. Compared with the arousal and suppression of public opinion, the guidance of public opinion is a more indirect, flexible and subtle way of dealing with public opinion (Chan, 2007). Thus, strong government tend to provide correct guidance to public opinion and be more capable to prevent conflicts on network and in real life (Chan, 2007; Xiang \& Wang, 2014). 


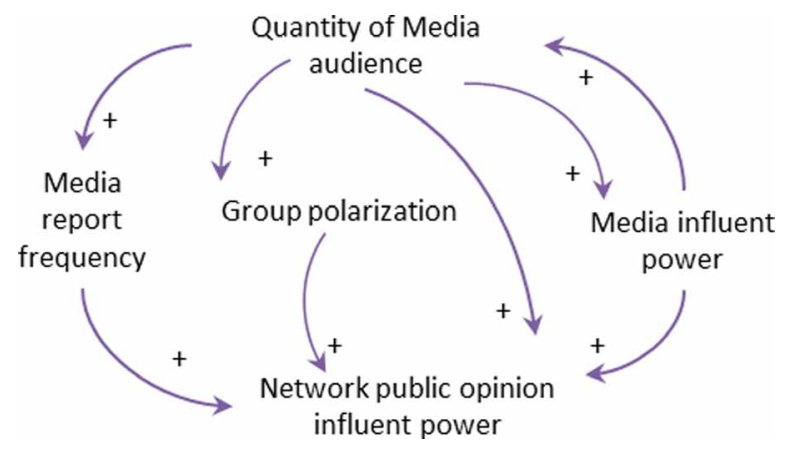

Government attention degree is the extent to which government is concerned about whether certain events trigger public opinion on network. High government attention degree indicates that government is interested in resolving the issues related with these events. Therefore, important events usually have high government attention degree.

The platforms where government disseminates information are important nodes when public opinion spreads. Government can release status of problem solving, update of progress, and measures for fixing problems. In this way, netizens know how public opinion develop. Thus, they will not feel panic or anxious. The openness of government regarding information release will guide netizens' opinion and weaken group polarization.

Management degree of government refers to the extent to which government controls the spread of public opinion for stabilizing social order. Government can take measures to decrease damages caused by public opinion on network, to increase government credibility, and to reduce the negative influence caused by public opinion on network. The measures include responding to public opinion swiftly, releasing authoritative information timely, and establishing an effective response mechanism for public opinion crises. When public opinion spreads, government can take measures to relieve netizens' panic or anxiety. Based on the discussion of government, government attention degree, the openness of government, and management degree of government, this paper proposes a causal relationship model for government's role as shown in Figure 5.

Figure 5. A causal relationship model for government role

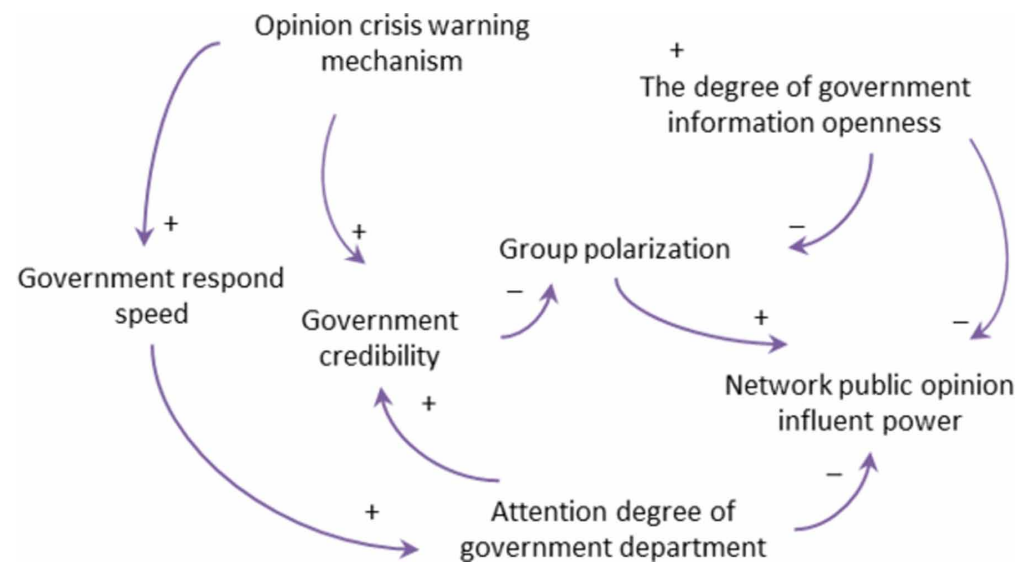




\section{A COMPREHENSIVE CAUSAL RELATIONSHIP MODEL}

In big data era, public opinion spreading on network have the characteristics of complexity, dynamics, and multi-mechanism. Public opinion's evolution and dissemination on network are affected by inner and outer dynamic factors, as well as the complexity of these factors. By integrating the roles that events, netizens, new media, and government play on the consequence of public opinion on network, this paper proposes a comprehensive causal relationship model as shown in Figure 6.

This model describes the factors, positive feedback, and negative feedback affecting the consequence of public opinion on network. The state of the system is indicated by accumulated stock. The flows reflect the stock change with time. The follow charts in the model are helpful for distinguishing variables, understanding the roles of factors, identifying feedback process, and performing management.

Consequence of public opinion on network is the stock quantity index, which indicates the condition of the system. The flow indexes represent the influence of netizens, new media, and government on the system as time changes. Figure 7 shows the flow of the influence with stock and flow indexes.

Variables and parameters in the model are described as below:

$$
E=W I T H L O O K U P(t+s+i),\left(\begin{array}{l}
{[(0,0)-(15,5.5)],(0,0.99),(1,1.33),(2,2.19),} \\
(3,3.31),(4,4.02),(5,5.66),(6,3.2),(7,2.1), \\
(8,1.9),(9,1.4),(10,1.2),(11,0.9),(12,0.4), \\
(13,0.2),(14,0.1),(15,0.03)
\end{array}\right)
$$

where:

- $E$ is the role of events;

- $t$ is the time period;

Figure 6. A comprehensive causal relationship model for factors affecting the consequence of public opinion on network

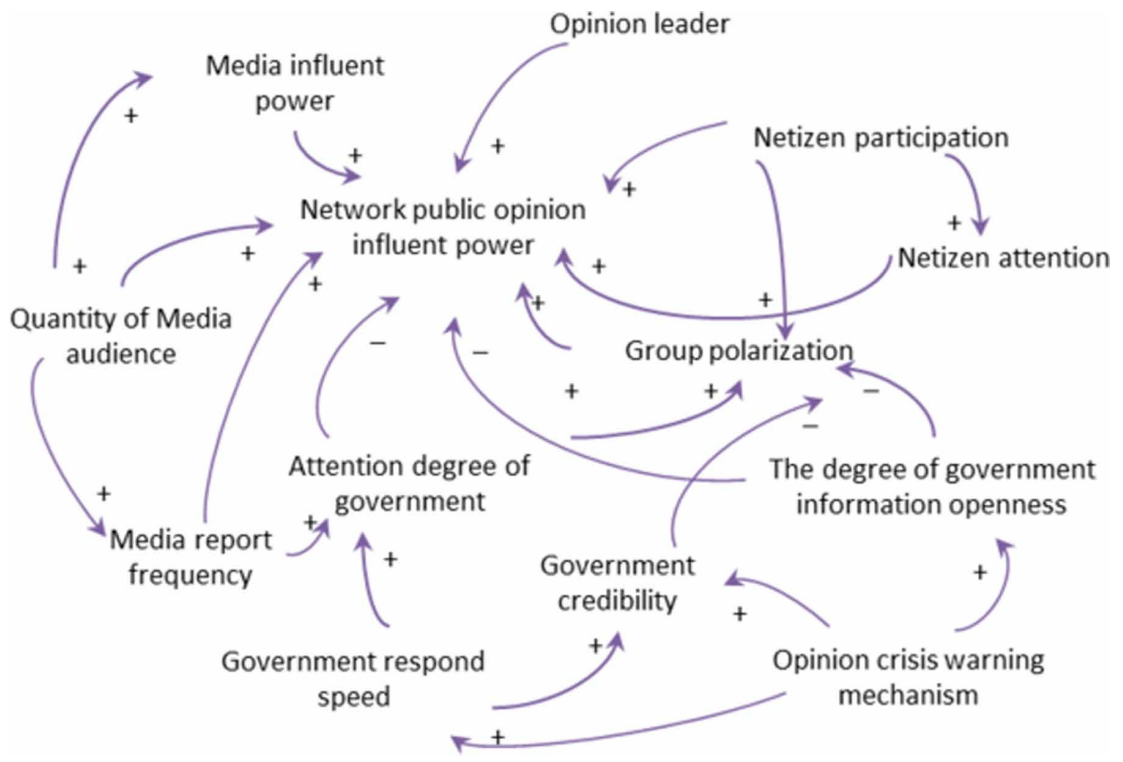


Figure 7. The flow of influence on the consequence of public opinion on network

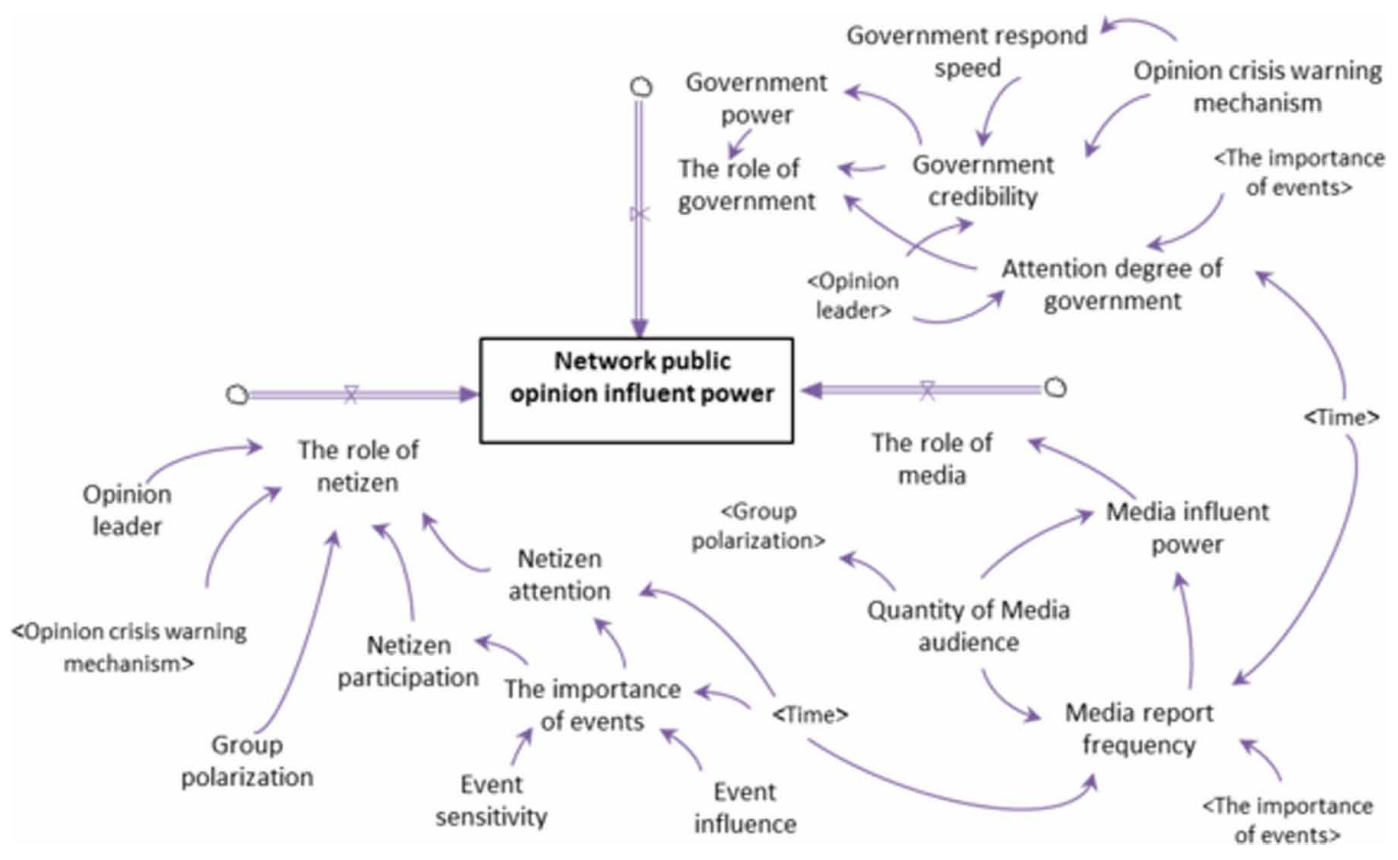

- $\quad s$ is the sensitivity of events;

- $i$ is the influence of events.

The role of events is determined by event sensitivity and event influence. The value can be obtained from expert scoring. Since the role of events will decrease with time, the speed of fading will be high in a later time. The function was adopted to demonstrate the change as below:

$$
G P=3.35^{*} \ln (A M)
$$

Media report frequency $=\left(\begin{array}{l}0.9752^{*} \text { The role of events } \\ +2.8^{*} e^{-0.05 *} \text { Audiencee quantity of media }\end{array}\right)+$ Time $e^{*} 0.01$

$$
M P=0.03 M F^{*} G P+0.003 S Q R T(A M)
$$

$$
M=M P^{*} 2.7
$$

where:

- $\quad G P$ is group polarization;

- $A M$ is audience of new media;

- $\quad M P$ is media influence power;

- $M F$ is media report frequency;

- $M$ is the role of media. 
When audience of new media grow, group polarization degree will enhance. At a later time, the role of group polarization is weaker with the continuous increase of media audience. Therefore, the function is adopted. The frequency of media report is positively related with time and the number of media audience. The weight value can be obtained from expert scoring. The frequency of media report will decrease with time. The influence of media will decrease as well. Function is adopted to simulate the influence of media:

$$
\begin{aligned}
& G A=0.923 E+0.03 O P e^{-t} \\
& G R=\text { if then else }(O W<7, S Q R T(O W), 1) \\
& G C=G R^{*} O W^{*} \ln (O L) \\
& G M=0.65 \mathrm{GC}+0.35 \mathrm{OW} \\
& G=0.4 G A+0.3 \mathrm{GC}+0.3 \mathrm{GM}
\end{aligned}
$$

where:

- $G A$ is government attention;

- $O P$ is the role of opinion leaders;

- $G R$ is government respond rate;

- $O W$ is the perfect degree of opinion crisis warning mechanism;

- $G C$ is credibility of government;

- $O L$ is the role of opinion leaders;

- $G M$ is government management degree to public opinion;

- $G$ is the role of government.

The choice function is adopted to demonstrate government response rate. A 1-10 scale is applied to measure warning mechanisms for public opinion crises. Assume that the maximum of the threshold is 7 , when government response rate is no longer increased due to some objective conditions. In addition, because government response rate is a process of learning and training, a delay function is adopted. The initial value of government response rate is set as 1 . The delay time is set as one month. Moreover, the increase of the government response rate requires training. Therefore, a delay function is applied to reflect the delay process:

$$
\begin{aligned}
& N A=E+0.01 e^{-t} \\
& N=\left(0.294 N A+0.3 S Q R T\left(N Q^{*} \frac{G P}{1.00011 e^{-0.06}}\right)+6 / S Q R T\left(O W^{*} O L\right)\right. \\
& N P O P=1.6 M-0.31 G+1.8 N
\end{aligned}
$$


where:

- $\quad N A$ is netizen attention degree;

- $\quad N$ is the role of netizens;

- $\quad N Q$ is the number of netizens who participate the process;

- $\quad N P O P$ is influence power of public opinion over network.

Affected by netizens, media, and government, influence power of public opinion on network can be retrieved from expert scoring based on AHP with an initial value 0 .

\section{A SIMULATION FOR THE PROPOSED MODEL}

Vensim PLE is adopted to simulate the proposed model in this study. Based on the proposed model, we observe and analyze the impact of the influential factors in the simulation by changing the values of parameters according to the evolution process of public opinion on network. The simulation aims to explore how the factors affect the consequence of public opinion on network and to provide measures for guiding public opinion on network.

As shown in Figure 8, the impacts of events, netizen attention, and netizen grow fast at the beginning and then slow down.

Similar with Figure 8, Figure 9 shows that the impact of media reported frequency and media influence grow fast at the beginning and then slow down.

Similar with Figure 8 as well, Figure 10 shows that the impact of government department attention and quantum of government system grow fast at the beginning and then slow down. However, the speed of the decline is slower.

As shown in Figure 11, the mutual influence from the subsystems of netizen, media, and government grow first and then decline slowly.

Figure 8. The impact of events, netizen attention, and netizens
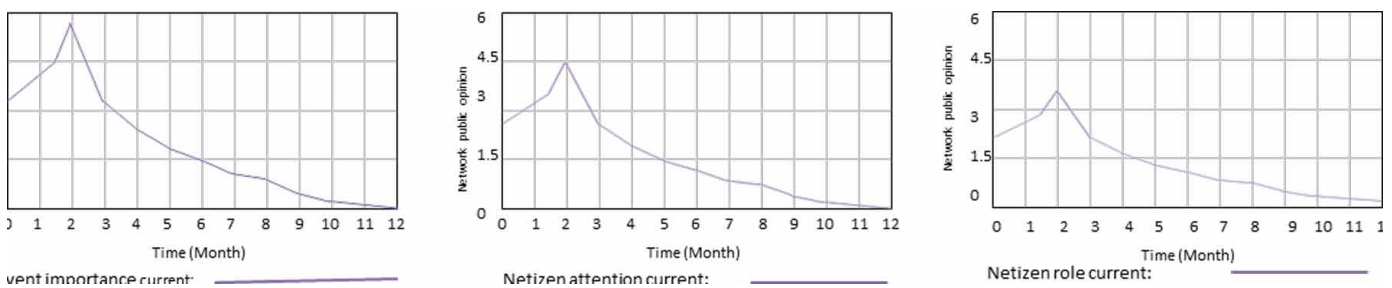

Figure 9. The role of the media

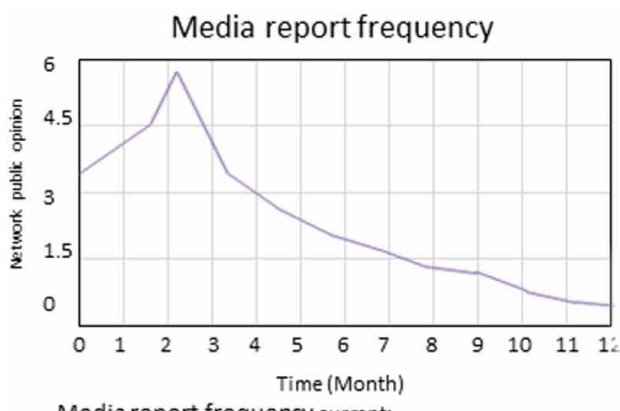

Media report frequency current:

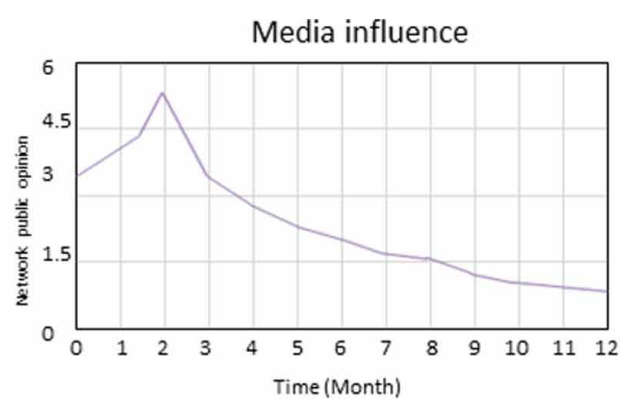

Media influence current : 


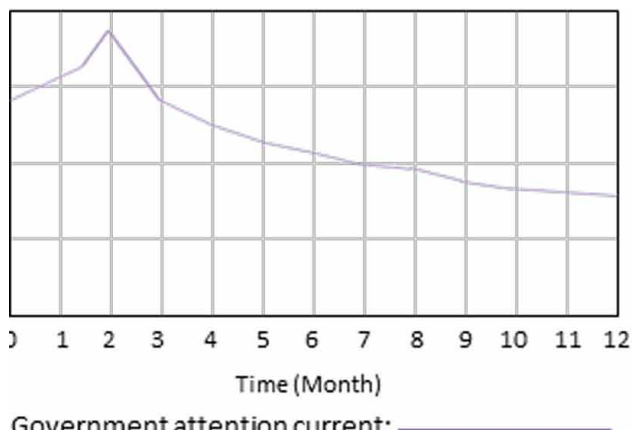

Government attention current:

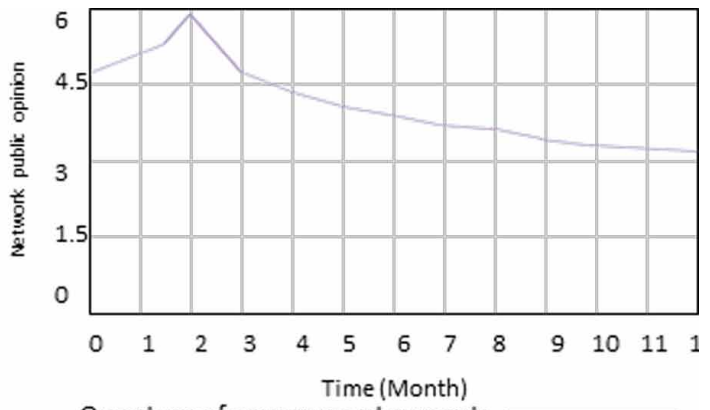

Quantum of government current:

Figure 11. The role of netizen, media, and government

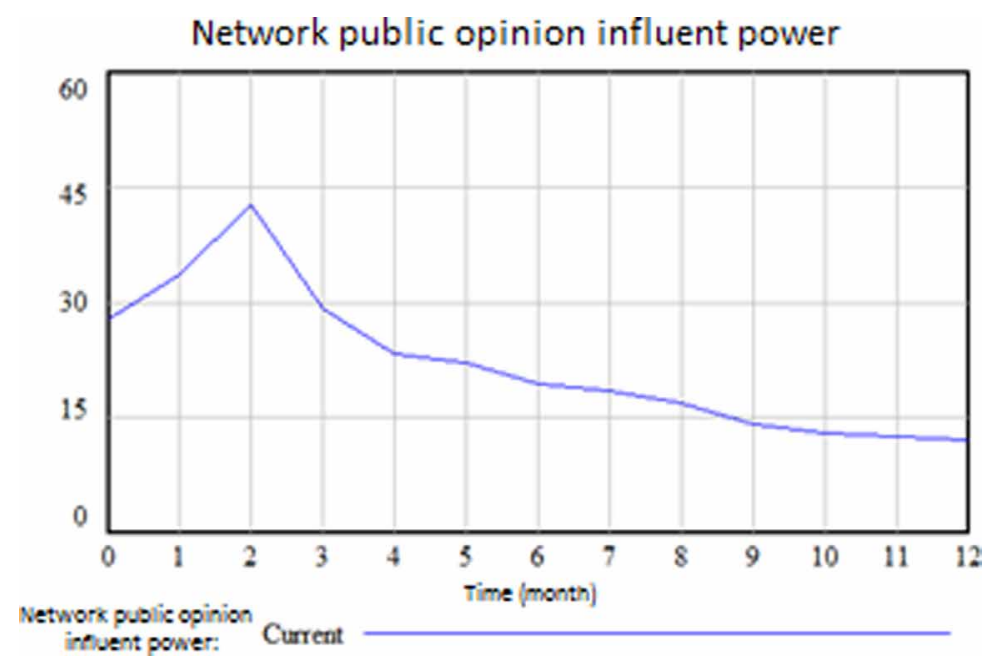

In the subsystem of netizen quantum, influence of public opinion on network come from group polarization and opinion leaders (Figure 12). The initial status is Curve 5. The role of group polarization decreases 20\% (Curve 3) and increases 20\% (Curve 4). The role of opinion leaders decreases 20\% (Curve 2) and increases 20\% (Curve 1). Changes of group polarization and the role of opinion leaders have impacts on the consequence of public opinion on network.

In the subsystem of media quantum, media report rate and the quantity of media audiences are the main factors influencing the consequence of public opinion on network (Figure 13). The initial status is Curve 5. Quantity of media audiences reduces 20\% (Curve 1) and increases 20\% (Curve 2). Media reported frequency decreases $20 \%$ (Curve 3) and increases $20 \%$ (Curve 4). The quantity of media audience and the frequency of media report affect the consequence of public opinion on network significantly.

In the subsystem of government quantum, government attention and warning mechanism for public opinion crisis are two factors that influence public opinion on network (Figure 14). The initial status is Curve 2. Government attention degree increases 20\% (Curve 1). Perfect degree of warning mechanism for public opinion crisis increases $20 \%$ (Curve 3). Government attention and warning mechanism for public opinion crisis impact the consequence of public opinion on network significantly. 
Figure 12. The quantum subsystem of netizens

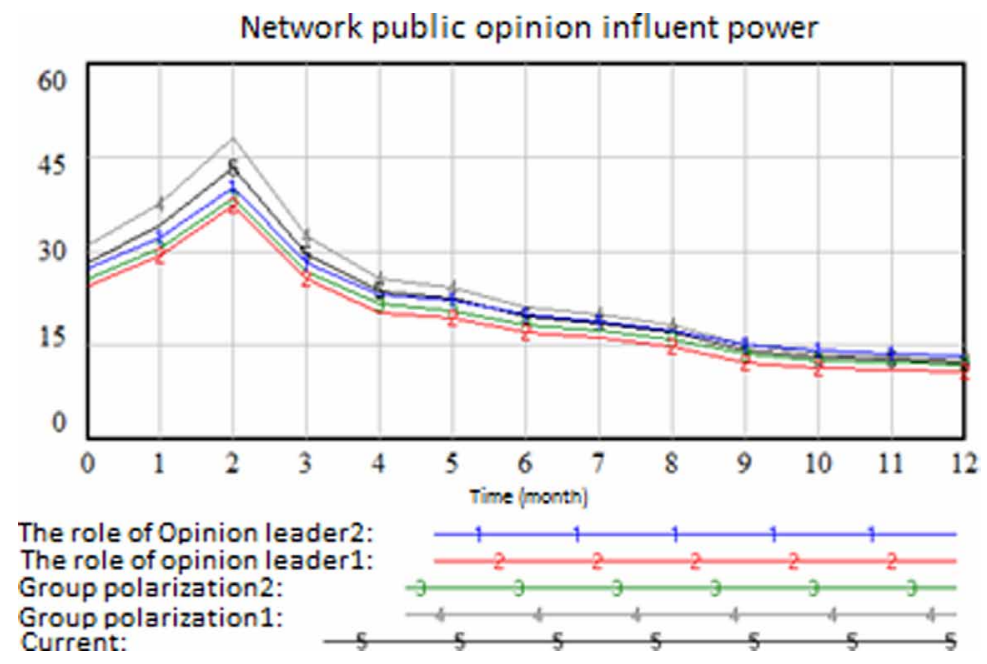

Figure 13. The quantum subsystem of media

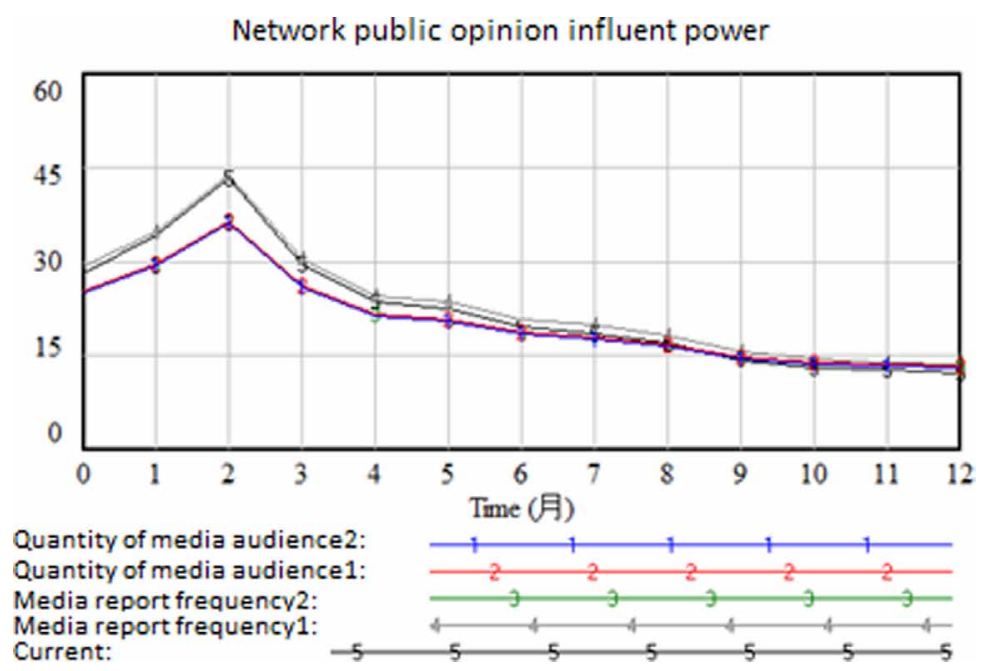

\section{CONCLUSION}

The development of new technologies provides new platforms for formation and dissemination of public opinion. Scholars have explored the factors that affect the evolution of public opinion on network. However, the findings are disparate and fragmented. Accordingly, this paper introduces eight mechanisms working on formation and dissemination of public opinion on network. Based on system dynamics, this paper further proposes a comprehensive causal relationship model to explore the factors affecting the consequence of public opinion on network. Particularly, the role of government is taken into consideration in this model. A simulation with Vensim PLE is conducted. The results of the simulation indicate that group polarization among netizens, opinion leaders, the quantity of media audience, the frequency of media report, government attention, and warning mechanism for public opinion crisis affect the consequence of public opinion on network significantly. 


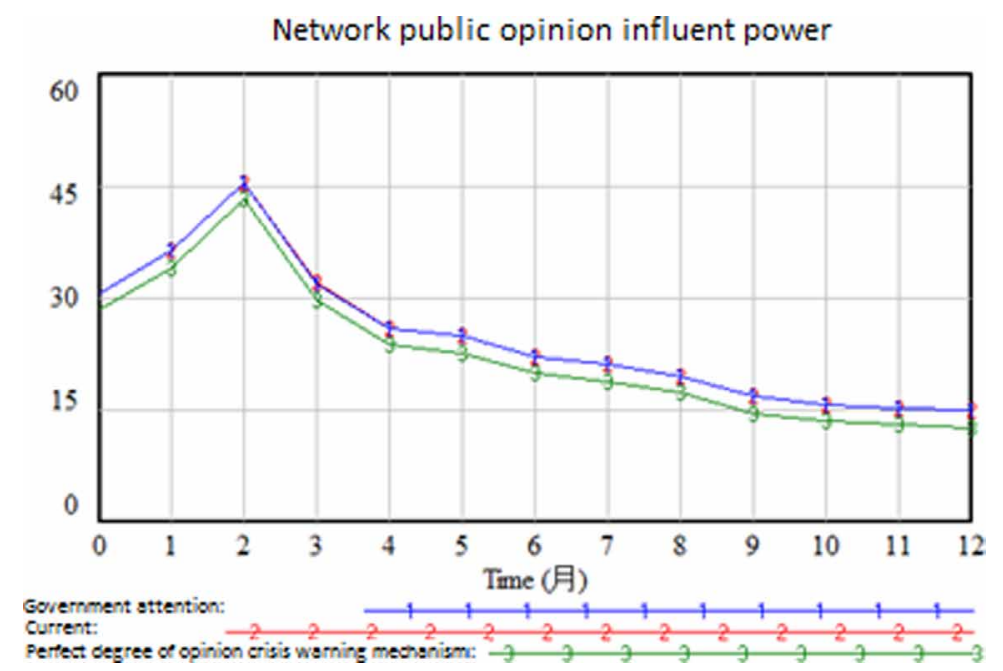

Given the characteristics of netizens and new media, government should have proper attitude to public opinion on network, take measures to overcome the side-effect of public opinion on network, and make quick responses to public opinion on network. Meanwhile, it is also import for government to monitor the spread of public opinion, so that crises and negative impact on the real world can be avoided. The goal for government is to take prompt action and to guide public opinion. Future research should collect real data of public opinion on network with big data techniques and validate the findings in this study.

\section{ACKNOWLEDGMENT}

This research is partially supported by the National Nature Science Foundation of China (NSFC) [ grant number 71473101]. 


\section{REFERENCES}

Asch, S. E. (1956). Studies of independence and conformity: I. A minority of one against a unanimous majority. Psychological Monographs, 70(9), 1-70. doi:10.1037/h0093718

Bennett, W. L., \& Iyengar, S. (2008). A new era of minimal effects? The changing foundations of political communication. Journal of Communication, 58(4), 707-731. doi:10.1111/j.1460-2466.2008.00410.x

Bi, Z., Xu, L., \& Wang, C. (2014). Internet of things for enterprise systems of modern manufacturing. IEEE Transactions on Industrial Informatics, 10(2), 1537-1546. doi:10.1109/TII.2014.2300338

Bineham, J. L. (1988). A historical account of the hypodermic model in mass communication. Communication Monographs, 55(3), 230-246. doi:10.1080/03637758809376169

Blanton, H., \& Christie, C. (2003). Deviance regulation: A theory of action and identity. Review of General Psychology, 7(2), 115-149. doi:10.1037/1089-2680.7.2.115

Castells, M. (2007). Communication, power and counter-power in the network society. International Journal of Communication, 1(1), 29.

Cha, M., Haddadi, H., Benevenuto, F., \& Gummadi, P. K. (2010). Measuring user influence in twitter: The million follower fallacy. ICWSM, 10(10-17), 30 .

Chan, A. (2007). Guiding public opinion through social agenda-setting: China's media policy since the 1990s. Journal of Contemporary China, 16(53), 547-559. doi:10.1080/10670560701562267

Chen, Y., \& Chen, H. (2016). Innovation and social media: Cultural impacts on the opinion influence process in brand communities. Journal of Industrial Integration and Management, 1(4). doi:10.1142/S2424862216500135

Chen, Y., Chen, H., Gorkhali, A., Lu, Y., Ma, Y., \& Li, L. (2016). Big data analytics and big data science: A survey. Journal of Management Analytics, 3(1), 1-42. doi:10.1080/23270012.2016.1141332

Chong, D., \& Druckman, J. N. (2007a). A theory of framing and opinion formation in competitive elite environments. Journal of Communication, 57(1), 99-118.

Chong, D., \& Druckman, J. N. (2007b). Framing public opinion in competitive democracies. The American Political Science Review, 101(4), 637-655. doi:10.1017/S0003055407070554

Corbett, M. (1991). American public opinion: Trends, processes, and patterns. Longman Publishing Group.

Cui, Q., \& Jiang, W. (2018). Panel data study on the appropriate proportion of personal expenses in total health expenditure in China. Journal of Management Analytics, 5(1), 18-31. doi:10.1080/23270012.2017.1410862

Davison, W. P. (1958). The public opinion process. Public Opinion Quarterly, 22(2), 91-106. doi:10.1086/266770

Di, G. Q., Zeng, H. Y., \& Le, Z. J. (2012). System dynamics model and simulation of network public opinion. Information Journal, 31(8), 12-20.

Ding, X. J. (2015). Research on Propagation model of network public opinion based on SIR and SNS. Computer simulation, 32(1), 241-247.

Domingos, P., \& Richardson, M. (2001, August). Mining the network value of customers. In Proceedings of the seventh ACM SIGKDD international conference on Knowledge discovery and data mining (pp. 57-66). ACM; . doi: $10.1145 / 502512.502525$

Eachempati, P. (2017). Change Management in Information Asset. Journal of Global Information Management, 25(2), 68-87. doi:10.4018/JGIM.2017040105

Fan, Y. (2017). Research on factors influencing an individual's behavior of energy management: A field study in China. Journal of Management Analytics, 4(3), 203-239. doi:10.1080/23270012.2017.1310000

Foote, N. N., \& Hart, C. W. (1953). Public opinion and collective behavior. In Group relations at the crossroads. New York: Harper \& Brothers.

Goldenberg, J., Libai, B., \& Muller, E. (2001). Talk of the network: A complex systems look at the underlying process of word-of-mouth. Marketing Letters, 12(3), 211-223. doi:10.1023/A:1011122126881 
Guo, F. L., Shao, Z. J., \& Yan, J. (2015). Network Structure of Opinion Leaders in Network Public Opinion Events and Its Political Participation Implication. [Social Science Edition]. Journal of Northeastern University, $17(2), 169-174$.

Hoffman, L. H., Glynn, C. J., Huge, M. E., Sietman, R. B., \& Thomson, T. (2007). The role of communication in public opinion processes: Understanding the impacts of intrapersonal, media, and social filters. International Journal of Public Opinion Research, 19(3), 287-312. doi:10.1093/ijpor/edm014

Hung, S.-Y., Huang, W.-M., Yen, D. C., Chang, S.-I., \& Lu, C.-C. (2016). Effect of information service competence and contextual factors on the effectiveness of strategic information systems planning in Hospitals. Journal of Global Information Management, 24(1), 14-36. doi:10.4018/JGIM.2016010102

Katz, E., \& Lazarsfeld, P. F. (1955). Personal influence: The part played by people in the flow of mass communications. Routledge.

Khatwani, G., \& Srivastava, P. R. (2017). An optimization model for mapping organization and consumer preferences for internet information channels. Journal of Global Information Management, 25(2), 88-115. doi:10.4018/JGIM.2017040106

Kock, N., Del Aguila-Obra, A. R., \& Padilla-Melendez, A. (2009). The Information Overload Paradox: A structural equation modeling analysis of data from New Zealand, Spain, and the USA. Journal of Global Information Management, 17(3), 1-19. doi:10.4018/jgim.2009070101

Lazarsfeld, P. F., Berelson, B., \& Gaudet, H. (1944). The people's choice: How the voter makes up his mind in a Presidential Campaign. New York: Columbia University Press.

Lee, H., Choi, J., Kim, K. K., \& Lee, A. R. (2014). Impact of anonymity on information sharing through internal psychological processes: A case of South Korean online communities. Journal of Global Information Management, 22(3), 57-77. doi:10.4018/jgim.2014070103

Li, S., Xu, L. D., \& Zhao, S. (2015). The internet of things: A survey. Information Systems Frontiers, 17(2), 243-259. doi:10.1007/s10796-014-9492-7

Li, S., Xu, L. D., \& Zhao, S. (2018). 5G Internet of Things: A survey. Journal of Industrial Information Integration, 10,1-9. doi:10.1016/j.jii.2018.01.005

Li, X. (2009). Social System Dynamics. Fudan University Press.

Liu, J. M. (2001). Public Opinion Propagation. Beijing: Tsinghua University Press.

Ma, N., \& Liu, Y. (2014). Superedge Rank algorithm and its application in identifying opinion leader of online public opinion super network. Expert Systems with Applications, 41(4), 1357-1368. doi:10.1016/j. eswa.2013.08.033

Moscovici, S. (1985). The age of the crowd: A historical treatise on mass psychology. Cambridge University Press.

Mutz, D. C., \& Soss, J. (1997). Reading public opinion: The influence of news coverage on perceptions of public sentiment. Public Opinion Quarterly, 61(3), 431-451. doi:10.1086/297807

Nelson, D., Pillepich, A., Genel, S., Vogelsberger, M., Springel, V., Torrey, P., . . Hernquist, L. (2015). The illustris simulation: Public data release. Astronomy and Computing, 13, 12-37. 10.1016/j.ascom.2015.09.003

Ning, M., Yijun, L., Ruya, T., \& Qianqian, L. (2012, December). Recognition of online opinion leaders based on social network analysis. In International Conference on Active Media Technology (pp. 483-492). Springer, Berlin, Heidelberg.

Noelle-Neumann, E. (1993). The spiral of silence: Public opinion, our social skin. University of Chicago Press.

Pan, Z., \& Kosicki, G. M. (1996). Assessing news media influences on the formation of Whites' racial policy preferences. Communication Research, 23(2), 147-178. doi:10.1177/009365096023002001

Pijanowski, B. C., Tayyebi, A., Doucette, J., Pekin, B. K., Braun, D., \& Plourde, J. (2014). A big data urban growth simulation at a national scale: Configuring the GIS and neural network based land transformation model to run in a high performance computing (HPC) environment. Environmental Modelling \& Software, 51, 250-268. doi:10.1016/j.envsoft.2013.09.015 
Powell, N. J. (1951). Anatomy of public opinion. New York: Prentice-Hall.

Price, V. (1989). Social identification and public opinion: Effects of communicating group conflict. Public Opinion Quarterly, 53(2), 197-224. doi:10.1086/269503

Price, V., \& Roberts, D. F. (1987). Public opinion processes. In Handbook of communication science (pp. 781-816). Sage.

Qu, W. G., \& Pinsonneault, A. (2011). Country environments and the adoption of IT outsourcing. Journal of Global Information Management, 19(1), 30-50. doi:10.4018/jgim.2011010102

Rogers, E. M., \& Cartano, D. G. (1962). Methods of measuring opinion leadership. Public Opinion Quarterly, 26(3), 435-441. doi:10.1086/267118

Song, B., Zhu, J. M., \& Huang, Q. F. (2014). Network public opinion grooming model based on cluster dynamics and evolutionary game theory. Systems Engineering Theory \& Practice, 11, 2984-2994.

Stelzner, M. A. (2010). 2010 Social media marketing industry report. Social Media Examiner. Retrieved from http://www.socialmediaexaminer.com/social-mediamarketing-industry-report-2010/

Su, G. Q., \& Lan, Y. X. (2013). Research on the Diffusion Model of Network Rumor of Emergency based on SIR. Journal of the Chinese People's Armed Police Force Academy, 29(4), 90-92.

Teoh, S. Y., \& Chen, X. (2013). Towards a strategic process model of governance for Agile IT Implementation: A healthcare information technology study in China. Journal of Global Information Management, 21(4), 17-37. doi:10.4018/jgim.2013100102

Tian, Y. L., Xu, X. F., \& Ma, X. L. (2011). Analysis of influencing factors of network public opinion based on system dynamics. Journal of Qingdao University: Natural Science, 24(1), 72-77.

Van Der Knijff, J. M., Younis, J., \& De Roo, A. P. J. (2010). LISFLOOD: A GIS-based distributed model for river basin scale water balance and flood simulation. International Journal of Geographical Information Science, 24(2), 189-212. doi:10.1080/13658810802549154

Wang, L. H. (2003) Overview of public opinion research. Tianjin: Tianjin academy of social science press.

Wang, P., Chaudhry, S., \& Li, L. (2016). Introduction: Advances in IoT research and applications. Internet Research, 26(2). doi:10.1108/IntR-06-2015-0183

Watts, D. (2007). Challenging the influentials hypothesis. WOMMA Measuring Word of Mouth, 3(4), 201-211.

Watts, D. J., \& Dodds, P. S. (2007). Influentials, networks, and public opinion formation. The Journal of Consumer Research, 34(4), 441-458. doi:10.1086/518527

Wei, C. (2014). Research on the influence of new media technology development on network public opinion information work. Library and Information Work, 58(1), 30-34.

Whitmore, A., Agarwal, A., \& Xu, L. (2015). The Internet of Things- A survey of topics and trends. Information Systems Frontiers, 17(2), 261-274. doi:10.1007/s10796-014-9489-2

Xiang, L. L., \& Wang, Q. (2014). Research on the evolvement characteristic and governance mechanism of network public opinion crisis under the background of information publicity. Information Science, 4, 26-30.

Xie, P. (2014). Influence of network opinion leaders on the evolution of public opinion from the perspective of network group events. Chinese Journal of Scientific and Technical Periodical, 2.

Xu, L., \& Duan, L. (2018). Big data for cyber physical systems in industry 4.0: A survey. Enterprise Information Systems. doi:10.1080/17517575.2018.1442934

Xu, L., Xu, E., \& Li, L. (2018). Industry 4.0: State of the art and future trends. International Journal of Production Research. doi:10.1080/00207543.2018.1444806

Xu, L. D., He, W., \& Li, S. (2014). Internet of things in industries: A survey. IEEE Transactions on Industrial Informatics, 10(4), 2233-2243. doi:10.1109/TII.2014.2300753 
Yuan, G. P., \& Xu, X. B. (2015). The emergency event public opinion research based on system dynamic. Information Science., 10, 52-56.

Zeng, H. Y. (2012). Research on Early Warning of Network Public Opinion Crisis Based on System Dynamics. Jiangxi University of Finance and Economics.

Zeng, R. X., Wang, C. X., \& Chen, Q. (2014). A Comparative Study on the Stage and Model of Network Public Opinion. Information Journal, 5, 119-124.

Zhou, H. D., Wang, G. H., \& Fang, F. J. (2012). Research on the network public opinion dissemination mechanism of enterprise crisis-take the "Sinian Dumpling" event as an example. Electronic government, 10, 56-63.

Ge Gao, PhD, the post doctor of Vienna University of Economic and Administration in Information Management, researcher in Production management department, Vienna University of Economic and Administration Vienna University of Economic and Administration. Professor in Management Science and engineering, management school, Jilin university. Published more than 40 papers. Interested fields: information management, business process reengineering, IT project management

Tianyong Wang, Associate prof, fields of interest: e-government management, public opinion management.

Xianrong (Shawn) Zheng is an Assistant Professor of Information Technology and Decision Sciences Department, Old Dominion University, Norfolk, Virginia, United States. He received his Ph.D. degree in Computer Science from Queen's University, Canada. His research areas are Computing and Informatics. His research interests are Cloud Computing, Big Data, E-commerce, and FinTech. He is a member of the ACM, the IEEE, and the AIS. Also, he is a Technical Program Committee Member of IEEE International Conference on Internet of Things (IEEE ICIOT 2018-2019).

Yong Chen is an assistant professor of Management Information Systems at Texas A\&M International University, Laredo, USA. Professor Chen earned his Ph.D. in information technology from Old Dominion University, USA. His research interests include information systems, information security, mobile payment, and social media. Professor Chen has published over 30 refereed papers in journals including Internet Research, Information Technology and Management, Systems Research and Behavioral Science, and Journal of Computer Information Systems.

Xiaobo Xu is a Professor of Management Information Systems at the American University of Sharjah, United Arab Emirates. He received his BE in Management Engineering from East China University of Science and Technology and his Ph.D. in Management Information Systems from the University of Mississippi. His primary research interests include information systems project success, business model innovation, research methodologies, e-commerce success, etc. His published articles appear in Project Management Journal, Information Technology \& Management, Information Systems Frontiers, International Journal of Information Management, and Internet Research among others. 